\title{
Chapter 7 \\ Essential Biodiversity Change Indicators for Evaluating the Effects of Anthropocene in Ecosystems at a Global Scale
}

\author{
Cristina Branquinho, Helena Cristina Serrano, Alice Nunes, Pedro Pinho, \\ and Paula Matos
}

\begin{abstract}
Understanding and predicting the impact of global change drivers on biodiversity, the basis of the delivery of goods and services to humans, is a critical task in the Anthropocene Era. This has led to the development of international monitoring networks and frameworks to evaluate changes in biodiversity, the Essential Biodiversity Variables, though still somewhat ineffective. Biodiversity drivers have changed their relative importance in time and space, e.g. due to policies to combat air pollution, the increasing nitrogen pollution or climate change. Hence, to monitor their impact on biodiversity in space and time, we need appropriate Biodiversity Change Indicators and Surrogates, measured through distinct metrics. In this chapter, we propose a conceptual model to select the most cost-effective metrics of biodiversity-change based on both the type and intensity of the drivers that limit or impact biodiversity, and the nature of the Essential Biodiversity Variables which may be affected in each case. We propose ecophysiology-based metrics for low intensity limiting/impacting drivers, affecting organisms' individual performance; trait-based metrics for medium intensity drivers, affecting the ecological performance of sensitive species before tolerant ones, changing species abundance and community functional traits; taxonomic-based metrics for high driver intensities which may culminate in species loss. We further discuss the utility of remote sensing data to measure some of these indicators or surrogates, allowing to upscale and/ or generalize spatial and temporal information.
\end{abstract}

Keywords Biodiversity $\cdot$ Driver $\cdot$ Surrogates $\cdot$ Metrics

\footnotetext{
C. Branquinho $(\varangle) \cdot$ H. C. Serrano $\cdot$ A. Nunes $\cdot$ P. Pinho $\cdot$ P. Matos

Centre for Ecology, Evolution and Environmental Changes, Faculdade de Ciências,

Universidade de Lisboa, Lisbon, Portugal

e-mail: cmbranquinho@fc.ul.pt; hcserrano@fc.ul.pt; amanunes@fc.ul.pt; ppinho@fc.ul.pt;

psmatos@fc.ul.pt
}

E. Casetta et al. (eds.), From Assessing to Conserving Biodiversity, 


\subsection{Introduction}

\subsubsection{The Need for Essential Biodiversity Variables}

The establishment of the Convention on Biological Diversity, at the Rio Earth Summit in 1992, has put biodiversity at the centre stage. Since then, several agreements have been signed, such as Contracting Parties' agreement on the United Nations Strategic Plan for Biodiversity 2011-2020, and associated Aichi Biodiversity Targets. Despite these agreements, biodiversity continued to change globally (Butchart et al. 2010; Dornelas et al. 2014; Tittensor et al. 2014), with ongoing species loss and/or changes in communities (without species loss), and our knowledge is still too small to understand the exact consequences for human's wellbeing and ecosystems resilience, presently and in the future. Hence, monitoring biodiversity change is an essential task for the XXI century, not only to assure we meet the proposed political goals (Aichi Targets for 2020, Parties to the United Nations, Convention on Biological Diversity, and Sustainable Development Goals for 2030 of the United Nations), but also to guarantee that the provision of basic ecosystem services (MEA 2005) is maintained, securing our survival on Planet Earth.

To monitor biodiversity-change at the global scale, harmonized observation system and timely data are needed (Pereira et al. 2013; Matos et al. 2017). In an attempt to solve this problem and simultaneously trying to answer to the question "what to monitor?", the Group on Earth Observations - Biodiversity Observation Network, proposed the concept of "Essential Biodiversity Variables" (Pereira et al. 2013). This process intended to be the basis of monitoring programs worldwide, and was inspired by the Essential Climate Variables, that guided the implementation of the Global Climate Observing System by the Parties of the United Nations Framework Convention on Climate Change (WMO 2010). The Essential Biodiversity Variables aim to help biodiversity observation-communities: (i) to harmonize monitoring, by identifying how variables should be sampled and measured; (ii) to help prioritize, by defining a minimum set of essential measurements to capture major dimensions of biodiversity change, complementary to one another and to other environmental change observation initiatives; (iii) to facilitate data integration, by providing an intermediate abstraction layer between primary observations and indicators (Pereira et al. 2013). In short, the Essential Biodiversity Variables framework aims to identify a minimum set of variables that can be used to inform scientists, managers and the public on global biodiversity change.

The Essential Biodiversity Variables framework recognizes three distinct levels of biodiversity information: (i) Primary Observations (i.e., raw data); (ii) Essential Biodiversity Variables; and (iii) Biodiversity Indicators (Collen et al. 2009) (Fig. 7.1). In a first attempt, the minimum set of Essential Biodiversity Variables aggregated candidate variables into six classes: "genetic composition," "species populations," "species traits," "community composition," "ecosystem structure," 


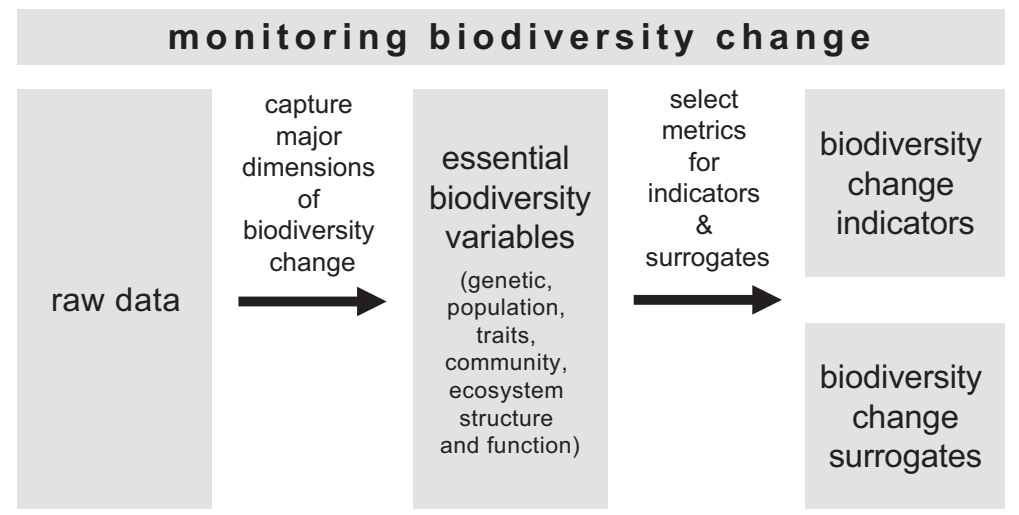

Fig. 7.1 Conceptual framework for "Monitoring Biodiversity Change" and for the selection of the metrics of indicators and surrogates that might reflect biodiversity change at the global scale

and "ecosystem function" (Pereira et al. 2013). The six classes proposed by Pereira et al. (2013) are now widely adopted as part of the essential biodiversity variables framework (Geijzendorffer et al. 2016; Chandler et al. 2017; Turak et al. 2017).

\subsubsection{The Challenges of Biodiversity Change Indicators}

Putting into practice a global monitoring network to track biodiversity change is far from being an easy endeavour. The Essential Biodiversity Variables framework will undoubtedly help global consistent reporting of changes in the state of biodiversity, but it is unlikely to contribute much to halt biodiversity decline, unless it can be effectively applied at scales relevant to decision-making regarding conservation (Henle et al. 2014). The complexity of biodiversity (different taxa, considerable species diversity within each, complex ecological interactions, numerous pressures interacting synergistically to impact multiple aspects of biodiversity, etc.) arises as a major obstacle, turning this purpose of tracking the trends and the state of biodiversity, in face of controllable and easily achievable conservation goals, a herculean task (Noss 1990; Brooks et al. 2014). In addition, major scientific challenges are faced when distilling biodiversity into a limited number of essential variables. These include: (i) identification of the taxa to be measured among the several that are important for biodiversity conservation and ecosystem services delivery; (ii) identification of a single variable for a critical aspect of biodiversity; (iii) the translation of information between different biological and geographical realms (e.g. terrestrial and marine); (iv) the heterogeneity of methods and data used for measuring and recording different components of biodiversity; and (v) the selection of appropriate metrics (units and scales) of measurement to ensure comparability between Essential 
Biodiversity Variables (Brummitt et al. 2017). Altogether, these barriers make it difficult to consistently aggregate variables across time, space and taxa (Turak et al. 2017). Documenting and quantifying global biodiversity change, remains a huge challenge due to sparse or biased data and a general lack of agreed international data standards.

Nearly 100 indicators have been proposed for the 2020 Convention on Biological Diversity targets (UNCBD 2011), but without significant advances on the indicator's practical application. The mid-term assessment of the Aichi Targets (Tittensor et al. 2014), suggested that while actions to counteract the decline of biodiversity have increased, so too have driver's intensity, resulting in a further deterioration in the state and trends of biodiversity. Meaning that to succeed, actions towards the Aichi targets will have to be supported by updated information on regional and global patterns of biodiversity change, on drivers of biodiversity change, and on the effectiveness of conservation policies (Pereira and Cooper 2006; Scholes et al. 2012; Tittensor et al. 2014; Proença et al. 2017).

A successful example was attained with typical ecological indicators, the epiphytic lichens (Matos et al. 2017). Since the industrial revolution (sulphur dioxide) to the present (nitrogen, land use, climate change), lichens have been used to track the major drivers of global change. Yet, currently the challenge is to harmonize methodologies, so they can be used at the global scale. Two protocols are applied at the continental scale, the United States and the European (Fig. 7.2). This work developed a framework to help bridge existing long-term monitoring data sets, investigating the compatibility of the interpretation of their outcomes using broadly accepted biodiversity metrics. This work showed that both methodologies generate similar interpretation trends. The framework developed incorporates measures of species richness, community shits and functional trait metrics. This enabled the use of available data and new data together in jointly analysis under a biodiversity change perspective, giving information on the drivers of change and on the effectiveness of conservation policies at the global scale.

However, very few biodiversity data sets of sufficient quality, across broad taxonomic, temporal and spatial scales are available for official reporting, all of which result in a reduced ability to reliably detect biodiversity change. This leads to information gaps and geographical, temporal and taxonomic biases in reporting efforts worldwide; for example, most data come from less biodiverse areas such as North America and Europe rather than biodiversity-rich areas (Collen et al. 2008; Mora et al. 2008; Pereira et al. 2012). Similarly, vertebrates are much better covered than other taxa (Pereira et al. 2012). In global assessments such as the Global Biodiversity Outlook 4 (CBD 2014), this leads to the predominant use of bird data for many biodiversity indicators (Pereira et al. 2012), undermining the comprehensiveness of the effects of global change on biodiversity and biasing also policy responses based on these reports. Information gaps and biases can originate from the indicator set used or from a lack of robust and reliable data. These constitute practical barriers that require increased efforts before biodiversity data can be used in assessments. Concerning the gaps in data, mobilization of existing data and the collection of new data could help fill current information gaps (Kot et al. 2010). The potential for 


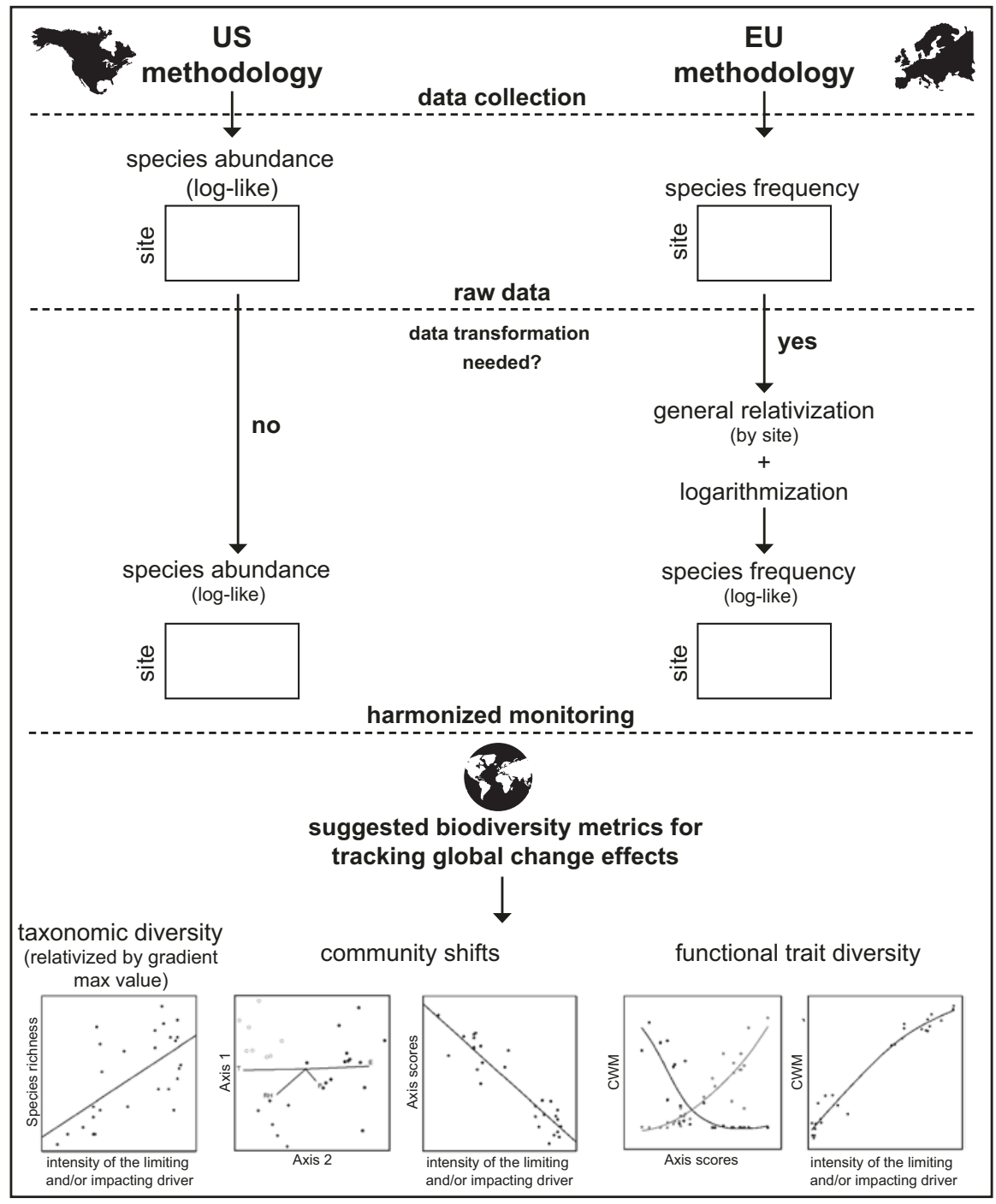

Fig. 7.2 Successful example of a harmonized monitoring framework to be included in the global monitoring network to track biodiversity change. This framework refers to the use of epiphytic lichen diversity collected with the most widely applied methodologies, the United States and European. (Adapted from Matos et al. 2017) 
data mobilization is internationally recognized, and several long-term initiatives have focused on mobilizing biodiversity data and metadata (e.g. the Global Biodiversity Information Facility - GBIF, and the Long-Term Ecological Research Network - LTER).

\subsubsection{The Need for Surrogates of Biodiversity Change}

Most species have not yet been described and even for those that are known, data on spatial distributions are sparse and often unreliable. Given the inability to properly and comprehensively cover all taxa, planning for biodiversity conservation requires surrogates of biodiversity. In an environmental context, a "surrogate" is a component of the system of concern that one can more easily measure or manage than others, and that is used as an indicator of the attribute/trait/characteristic/quality of that system (Mellin et al. 2011). The use of surrogates is important and often necessary because resource constraints in monitoring and management require costeffective yet useful ways to assess ecosystem responses and key ecological processes (Lindenmayer et al. 2015).

Surrogates can be roughly divided into taxonomic and environmental categories. Taxonomic surrogates are predominantly based on biological data and normally include known taxonomic groups, focal species, umbrella species, species assemblages, and various ecological classifications (Grantham et al. 2010; Lindenmayer et al. 2015; Hunter et al. 2016). Environmental surrogates are usually based on a mix of physical and biological data, subdivided into two types: those based on discrete classes (ecological classifications or land types) and surrogates where continuous data are analysed directly in the selection of areas. They can reflect drivers known to be important in determining the distribution of species and, modelled with species data, can be mapped more consistently, quickly, and inexpensively across large areas (Fig. 7.3). The choice of the drivers is determined also by data availability, spatial scale, choice of data merging techniques, biogeography, and perceptions about the importance of specific variables in shaping biological distributions.

There are four important common steps in the development of ecological surrogates: (i) identify well-developed goals for the use of ecological surrogates (McGeoch 1998; Collen and Nicholson 2014); (ii) develop a robust conceptual model of the system in question to then guide the identification of appropriate surrogates (Niemeijer and de Groot 2008); (iii) rigorously test the ecological surrogates (Bockstaller and Girardin 2003); and (iv) overcome widespread problems of translating the scientific knowledge on ecological surrogates in a way that effectively informs managers and decision-makers, or even the wider public (Halpern et al. 2012; Westgate et al. 2014) (Fig. 7.3).

Recently, Lindenmayer and co-workers (2015) developed a new conceptual Adaptive Surrogacy Framework to explicitly address five trade-offs: (i) whether it is better to employ surrogates or address (e.g. measure) an entity directly; (ii) the 


\section{the need to interpret biodiversity change indicators \& surrogates with limiting and/or impact drivers}
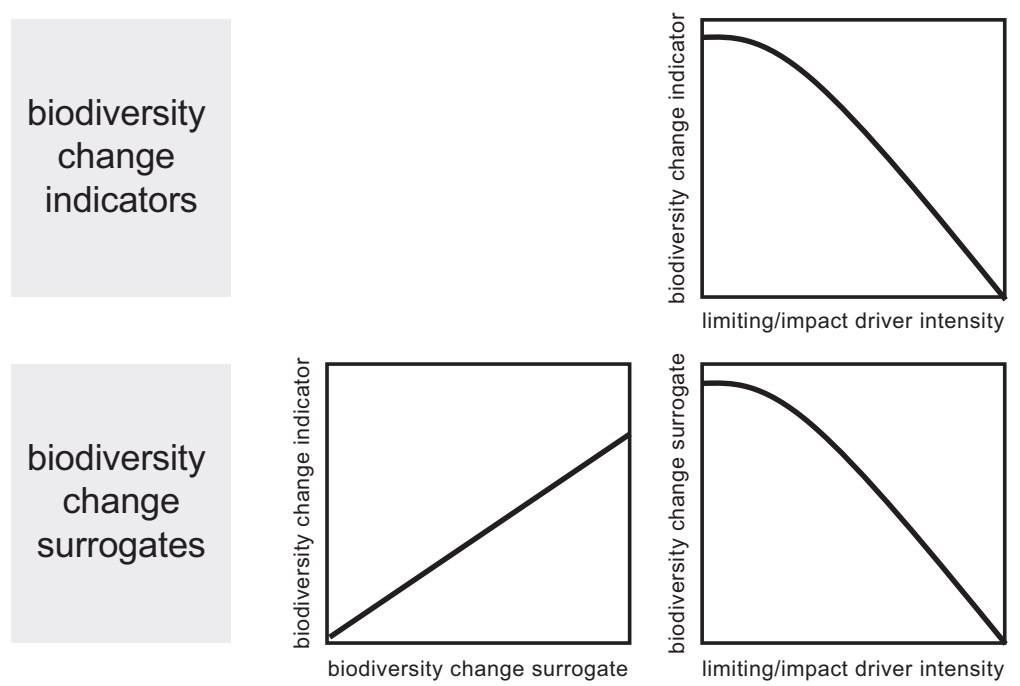

Fig. 7.3 Diagram representing the use of Indicators and Surrogates of Biodiversity Change. Before using Surrogates of Biodiversity Change (bottom-left), they need first to be modelled and validated in relation to the Biodiversity Change Indicator of interest (bottom-right) which must be related to changes in a limiting/impact driver (top-right)

accuracy versus generality of a surrogate; (iii) the temporal stability of a surrogate versus its ability to detect change over time; (iv) simple communication value versus communication complexity associated with caveats and details of methodology; and, (v) cost-effectiveness versus certainty.

\subsubsection{The Importance of Drivers Limiting or Impacting Biodiversity Change}

The preliminary analysis of biodiversity indicators showed that it requires additional information on non-biodiversity variables, i.e. the drivers limiting or impacting biodiversity in some way (Tittensor et al. 2014). These are essential to inform a specific objective of a policy target (e.g. progress in policy implementation, public awareness, and policy and management responses, such as the change in global surface temperature) and to provide an interpretation of the detected changes in biodiversity (e.g. driven by pollution or climate change), so that actions can be taken to address that problem. A driver is any natural or human induced 
pressure factor that directly or indirectly causes a change in an ecosystem. Whereas a direct driver unequivocally influences ecosystem processes, an indirect driver operates more diffusely, by altering one or more direct drivers. Some important anthropic direct drivers affecting biodiversity are habitat change, climate change, invasive species, eutrophication, overexploitation, and pollution (MEA 2005).

Changes in biodiversity are almost always caused by multiple interacting drivers working in space and over time, that can occur intermittently (such as droughts) or permanently (such as land-use) (MEA 2005). Though some drivers are global, the actual set of interactions that brings about an ecosystem change is more or less specific to a particular place (Ribeiro et al. 2013). The strength of a driver effect, however, is determined by a range of location-specific factors (MEA 2005). Therefore, it is crucial to identify and evaluate the intensity of the driver limiting or impacting biodiversity (recognized threats and pressures), and the actual positive or negative effects on physiological and ecological performance of individuals, species, communities, habitats and ecosystems. These non-biodiversity variables are not covered by the Essential Biodiversity Variables list (Pereira et al. 2013). Yet, comprehensive interpretation of biodiversity trends clearly requires the integration of other data, notably on drivers and pressures for biodiversity. This is crucial to decide which type of metric of biodiversity change indicator/surrogate should be selected for each Essential Biodiversity Variable.

\subsubsection{The Nature and Intensity of the Drivers from the Past to the Future}

Direct drivers vary in their importance within and among systems and in the extent to which they are increasing their impact. Historically, habitat and land use change have had the biggest impact on biodiversity across biomes. Overexploitation and invasive species have been important as well, and continue to be major drivers of change (MEA 2005). Pollution, in the past by metals and sulphur dioxide, and more recently the deposition of nitrogen and phosphorus, is expected to increase its impact, leading to declines in biodiversity across biomes. Climate change is projected to increasingly affect all aspects of biodiversity, from individual organisms, through populations and species, to ecosystem composition and function (MEA 2005).

Due to human activities and to climate change, ecosystems are experiencing changes from the local to the global scale (MEA 2005; Canadell et al. 2007). The impacts are of such magnitude that have led to the consideration of a new era - the Anthropocene (Zalasiewicz et al. 2010). Since the first warning by The Limits to Growth (Meadows et al. 1972), scientists have been trying to quantify the environmental, economic, and social limits to human activities on Earth. In a context of global change, Rockström et al. (2009), and more recently Steffen and co-workers 
(2015) analysed the safety of nine planetary systems (with great importance for human habitability on Earth) and concluded that the rate of biodiversity loss, climate change and eutrophication have already crossed the safety borders of the terrestrial system. On the other hand, they show that chemical pollution, although undeniably important, had not yet been quantified. All these changes in the planetary systems impact the structure and functioning of ecosystems and the consequent delivery of goods and services they provide. Managing and understanding complex systems such as our society or ecosystems, requires simplification. It is therefore essential the construction of a simple image with a limited set of relevant factors: the "Indicators \& Surrogates of Biodiversity Change".

\subsection{Objective and Rationale}

In the Era of Anthropocene and under the framework of the Essential Biodiversity Variables, the main aim of this work is to call attention for the need to develop Biodiversity Change Indicators and Surrogates to monitor biodiversity changes. These can only be interpreted and applied after knowing their relationship with the drivers that limit or impact biodiversity. We propose a conceptual model to select the most cost-effective metrics of biodiversity change, based on both the nature and the intensity of the drivers that limit or impact biodiversity. During the Anthropocene Era we expect most ecosystems to be affected by at least one anthropic driver (whether it is global or local). Some drivers, such as some pollutants (e.g. DDT) never existed in nature and others existed in much lower amounts or intensity than today (carbon dioxide or ammonia). Ecosystems are currently affected by drivers which limit or impact biodiversity with different intensities. In this work, we use the term 'Driver Intensity' to convey not only the amount but also the toxicity of the drivers affecting biodiversity. Additionally, driver's intensity changes over time. In the past, biodiversity was mostly affected by air pollution (e.g. sulphur dioxide and metals), while nowadays nitrogen pollution is the driver with stronger effects on biodiversity, particularly in rural areas. In the future, we expect changes in climate patterns due to climate change to become the most important driver. Sulphur dioxide in the atmosphere increased almost ten-fold during the industrial revolution (with its maximum in the 70s), whereas ammonia emissions increased more recently and with an intensity of approximately four-fold. Climate change effects on biodiversity are mostly related to changes in the deviation from average climatic variables, such as the case of global surface temperature (Fig. 7.4). Due to this, significant changes were only recently detected, and its intensity is still low in comparison with the magnitude of the previous drivers. Our conceptual model will be based on the selection of the most cost-effective biodiversity change metric having in mind the nature and intensity of drivers, and the nature of the Essential Biodiversity Variables. 


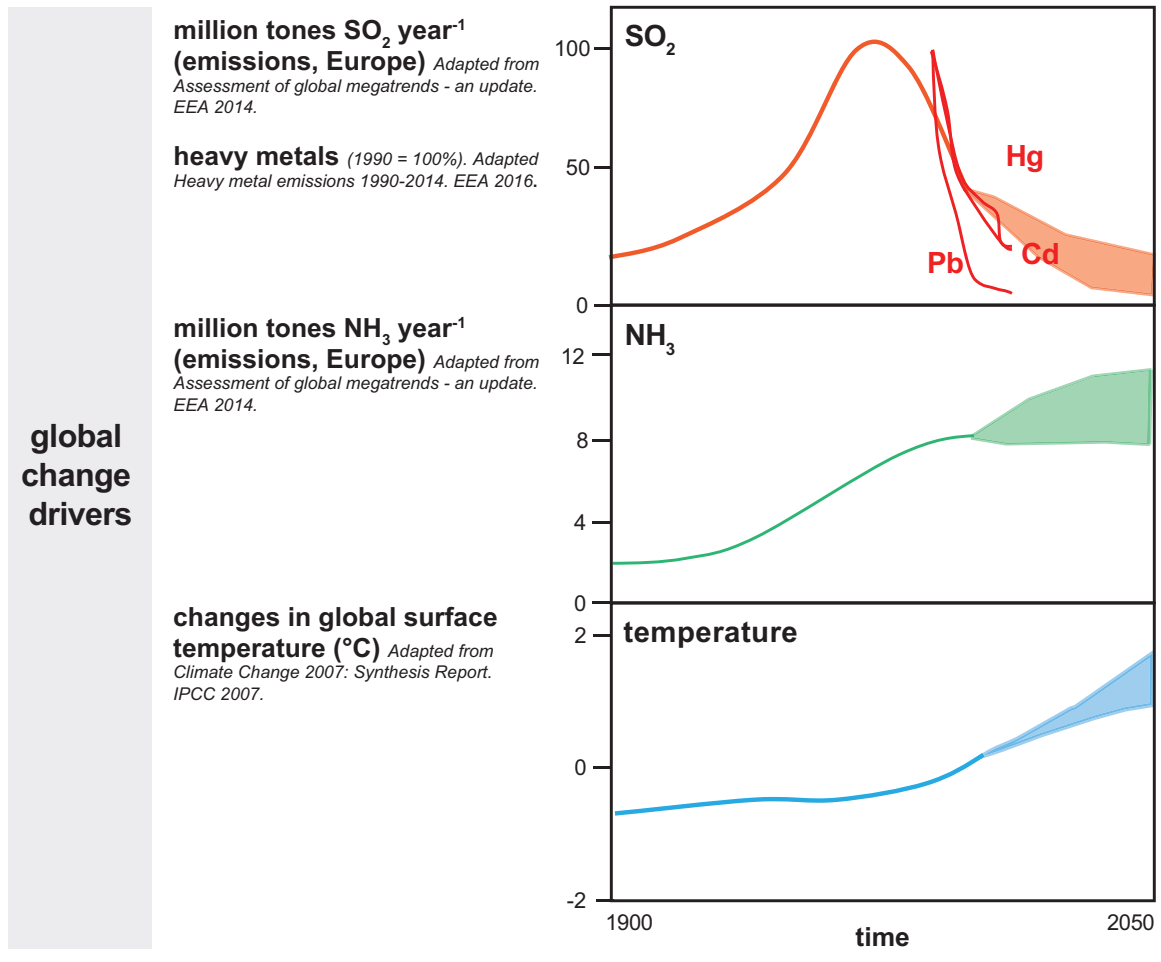

Fig. 7.4 Limiting and impacting drivers of biodiversity change over time. Emissions of gaseous (million tons of sulphur dioxide per year) and metal pollution (lead, mercury and cadmium emissions in relation to 1990), nitrogen pollution (ammonia emissions in tons per year) and climate change (global surface temperature change) since 1900 till present and predicted up till 2050. (Adapted from IPCC (2007) and EEA $(2014,2016)$ )

\subsection{How to Choose Biodiversity Change Metrics in Relation to Driver's Intensity}

\subsubsection{Low Intensity Drivers may Change Biodiversity Metrics from Genetic Composition to Species Populations}

When the limiting or impacting drivers are of low intensity (due to both nature or magnitude), we expect them to interfere with individuals' performance, but not to the point of jeopardizing their existence. Individuals physiological performance might be different due to differences in their genetic pool and on acclimation conditions (plasticity). When a population is subject to limiting or impacting drivers, the most sensitive individuals tend to have a lower physiological performance (e.g. lower growth) in comparison with the most tolerant ones, that are not affected for 


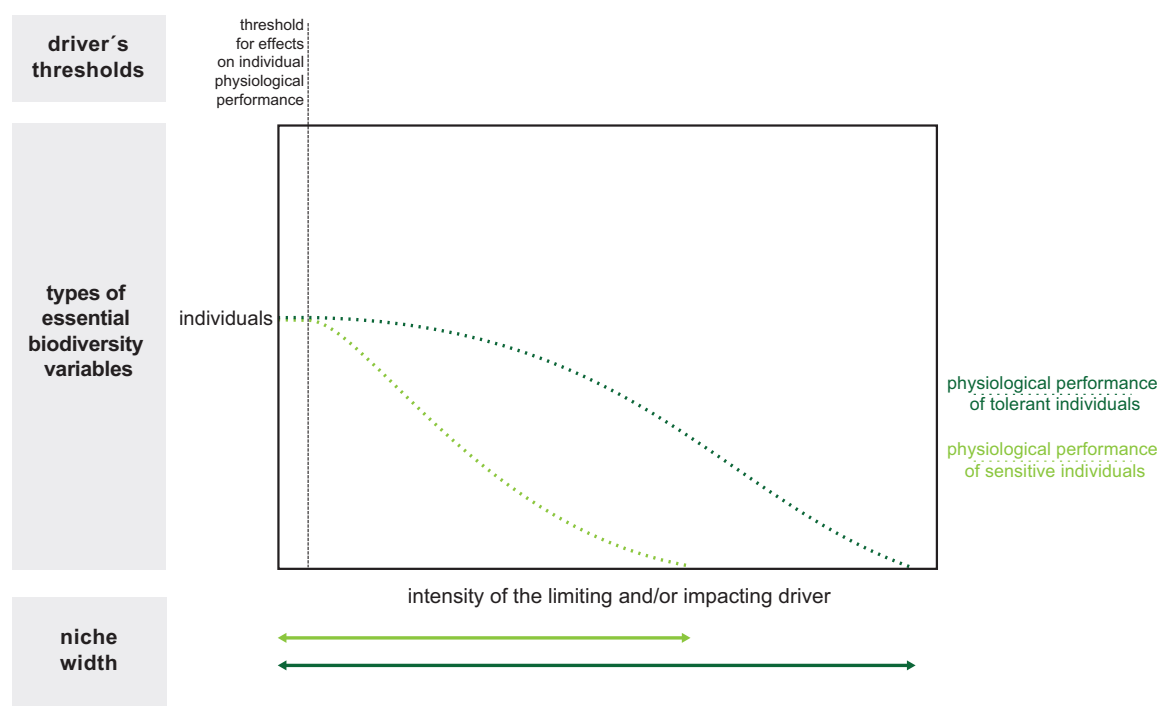

Fig. 7.5 Effect of the driver's intensity on Essential Biodiversity Variables, for individuals' performance. The decrease in physiological performance (dotted lines) of sensitive individuals is more abrupt than that of tolerant ones, though they show similar fundamental niches. Different starting points (genetic or phenotypic variability) of individual performance would also produce different ending points. The ecological performance (realised niche; double arrows) of the sensitive and tolerant individuals indicates their niche width and would be reflected in the biodiversity of the species population

the same driver intensity (Fig. 7.5). The amplitude of driver's intensity where sensitive and tolerant individuals grow determines their realised niche width (Fig. 7.5).

In the beginning there was the gene: one unit, more or less filled with variability (alleles) and prone to mutations that might expand biodiversity and drive evolution. An individual is a complex interaction of genes, with differences enough from the next to make it unique, but also limited within a common pool. Taxonomy studies these genetic pools, mostly by looking at the phenotypes, the physical expression of genes together with the environment, characterizing groups of similar individuals as a species, genus or phylum (e.g.). The more biodiverse a gene is (different alleles), the higher the chances for the outcome to be a more plastic phenotype, capable to withstand environmental variation (Fusco and Minelli 2010).

The fundamental niche concept is deeply connected with that of genetic pool: genes determine the limitations and plasticity ranges an individual can outstand. This concept of fundamental niche (theoretically, the widest range of abiotic conditions where a species can maintain a sustainable population (Hutchinson 1957)) can be considered one of the bases for biodiversity: different sets of abiotic conditions will encompass different performances for different individuals with different genetic backgrounds (Hutchinson 1991). Phylogeny intends to go a bit further than taxonomy, relating the species current taxonomic position to time and evolution. 
Both taxonomy and phylogeny are measures of biodiversity that are dependent on the definition of species. With time and environmental drivers in action, the gene pool might be reduced or modified to a point of no return (speciation or extinction).

To add complexity to these interactions, single individual's performance depends not only on their genetic pool, but also on the interaction with the community (other individuals of the same and of different species) and with limiting (soil, water, light, temperature) or impacting drivers (pollution, eutrophication, etc.). The fitness of the several single individuals (their physiological performance) determines the overall performance of the population. Thus, the fitness of the several populations, which all together make the species (ecological) performance, is a proxy for the species realised niche, the part of the fundamental niche that is in fact occupied by the species in natural conditions (Colwell and Rangel 2009). An ecosystem is thus, the combination of a specific community, in a particular set of abiotic conditionings (limiting drivers), that make it unique. A change in community composition or in limiting (edaphoclimatic factors) or impact drivers (e.g. climate change; pollution) will eventually result in a change in biodiversity and the ecosystem status.

In water and nutrients rich ecosystems, and without other abiotic stress drivers, the main limiting drivers for the establishment of an individual should be its dispersion ability to more empty areas and tolerance to interactions with other species (e.g. pathogens, parasites, herbivores). As more individuals occupy those empty spaces, competition arises (intra or interspecific), mostly for light in the case of primary producers, for example. On the other extreme, in poor and hostile ecosystems, low resource availability implies a stronger competitive drive between nearby individuals. Biodiversity here, is shaped by the width of the realised niches, more or less reduced from the fundamental niche width, according to competitive ability to reach or occupy the areas with more resources (Colwell and Rangel 2009; Hortal et al. 2015).

In the case of strong competition (intra or interspecific), the strongest competitor will occupy the areas with more resources, while the weakest one will be pushed to areas with higher abiotic stress, where it doesn't perform so well physiologically (Colwell and Fuentes 1975). In this case, for the weak competitors, the areas of higher ecological performance (abundance) will not be the areas of higher physiological fitness, against what common sense would dictate (McGill 2012). Biodiversity in these communities can change dramatically, if the established ecosystem equilibrium is disrupted by strong drivers, like changes in community composition (e.g. introduction of exotic species) or abiotic factors (e.g. climate change), see Fig. 7.6 for an example. Therefore, at the community level (individuals or even species), the measure of physiological performance vs. ecological performance, would integrate the local biodiversity drivers that affect it, from genes, to individuals, to community, reflected in the niche width. Thus, individual physiological performance of the population can be a good Biodiversity Change Metric that respond to low intensity drivers.

Consider two drivers affecting a community: biotic - competition (intra or interspecific); and environmental - a particular stress. The response of the individuals in the community to those local drivers will determine its biodiversity (Fig. 7.6). 


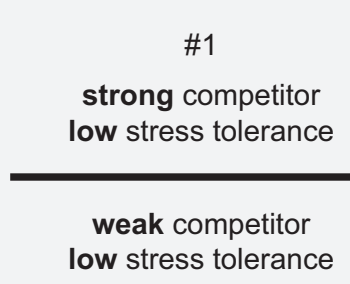

\#3

\section{physiological performance}
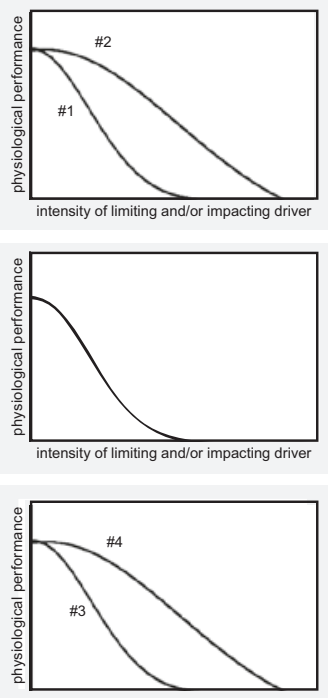

intensity of limiting and/or impacting driver

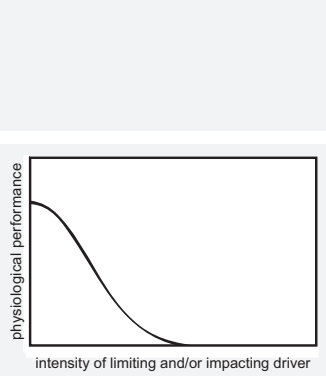

\#2

strong competitor

high stress tolerance

weak competitor

high stress tolerance

\section{\#4}

\section{outcome for biodiversity}

\section{Interaction of \#1 and \#2}

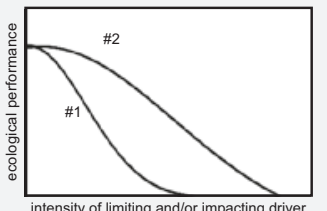

\#1 has a narrower realised niche than \#2 due to its low stress tolerance, so its distribution is limited to areas of lower stress. \#2 would be a widespread generalist species with potential to become invasive.

\section{Interaction of \#1 and \#3}
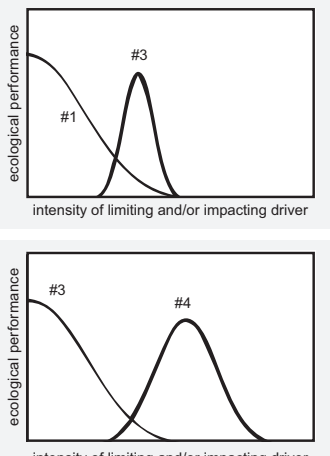

intensity of limiting and/or impacting driver

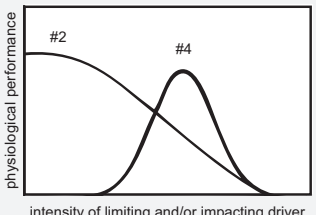

Competition between two low stress tolerants. The stronger competitor \#1 pushes \#3 to most stressful areas, resulting in a very narrow realised niche for \#3. The best physiological performance for both would be achieved in the low stress areas. \#3 would easily become a very rare species locally.

\section{Interaction of \#3 and \#4 (or \#1 and \#4)} Both \#3 and \#4 are weak competitors, so competition is not the driver for biodiversity. Because their stress tolerance is quite different, they can also occupy different areas without overlapping. The outcome is similar to that of the interaction between \#1 and \#4, but fin this case the reason is low competition due to the different stress limits. Although \#4 is not at its best physiological performance where its ecological performance is best, this is enough to sustain their population (e.g. Plantago almogravensis; Serrano et al. 2015) depending on the maintenance of those refuges, but still prone to high rarity locally.

\section{Interaction of \#2 and \#4}

\#2 being a much stronger competitor than \#4, it pushes \#4 to its limits of distribution (areas of high stress). These refuge areas for \#4 (unnecessarily stressful for \#2) are very feeble making this species prone to rarity.

For \#2 and \#3 there is no coexistence possible, as \#2 would dominate over the areas of \#3 fundamental niche, leaving not enough resources and driving \#3 to local extinction.

Fig. 7.6 Effect of the biodiversity change drivers in the physiological and ecological performance of two species with different characteristics 


\subsubsection{Intermediate Intensity Drivers May Change Biodiversity Metrics from Species Traits to Community's Composition}

The capacity of an ecosystem to withstand disturbances without shifting to an alternative ecosystem state, losing functions and services, defines ecosystem resilience (Holling 1973; Scheffer et al. 2001), and is tightly dependent on the ecosystems' biodiversity in all its facets (Pollock et al. 2017). Depending on the nature and intensity of the driver, these different facets may be hierarchically affected, from individual organism's performance to changes at the community level (de Bello et al. 2013). The selection of the appropriate Metrics to measure Biodiversity Change should, therefore, depend on the type or intensity of the driver. For that reason, and as suggested by this book title, assessing and conserving biodiversity to face the challenges posed by global change implies moving beyond a mere individual species approach.

As discussed in Sect. 7.3.1, when the drivers act on ecosystems at low intensity, they are expected to affect firstly the physiological performance of biological organisms (at the individual level), which in turn affect their fitness, e.g. growth, reproduction success. Only then, changes in the performance of populations or species may lead to changes in their abundance, determining a decrease in more sensitive species and/or an increase in the most tolerant ones (Cornwell and Ackerly 2009) (Fig. 7.7). This may be seen as a response of species ecological performance that, as

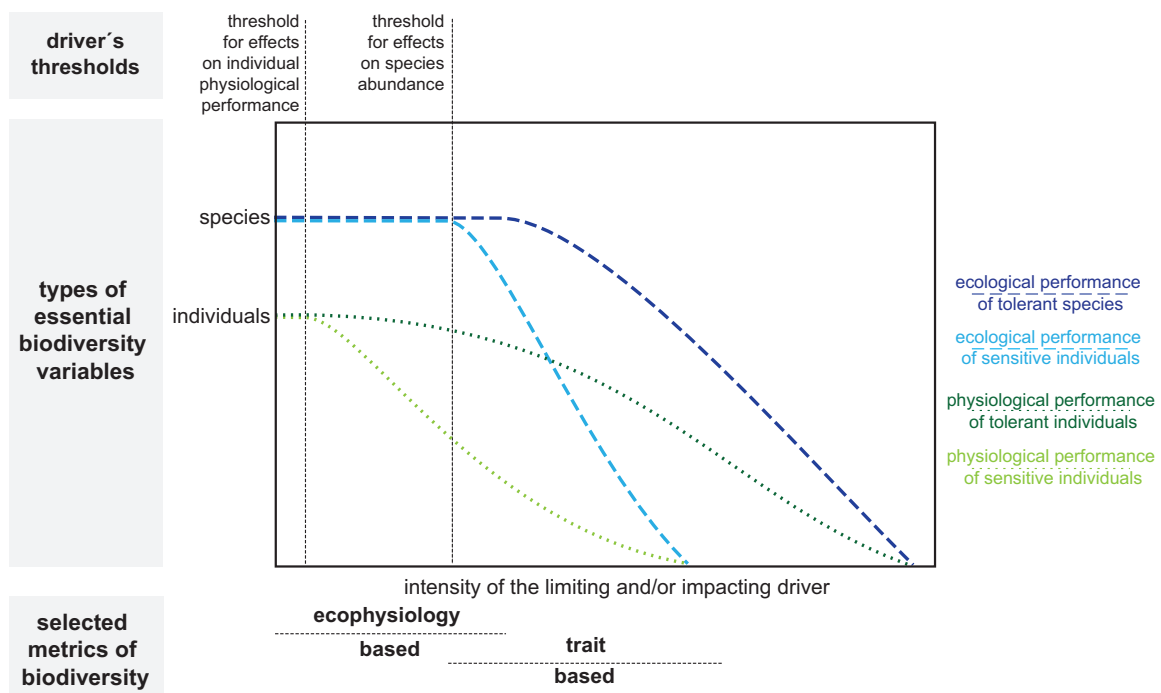

Fig. 7.7 Effect of the driver's intensity on Essential Biodiversity Variables at the individual and species performance level. A low intensity of the driver affects individual's performance, reflected by ecophysiology-based metrics. Increasing intensity of the driver will affect sensitive species before tolerant ones, leading to changes in species abundance and consequently to changes in community functional characteristics, reflected by trait-based metrics 


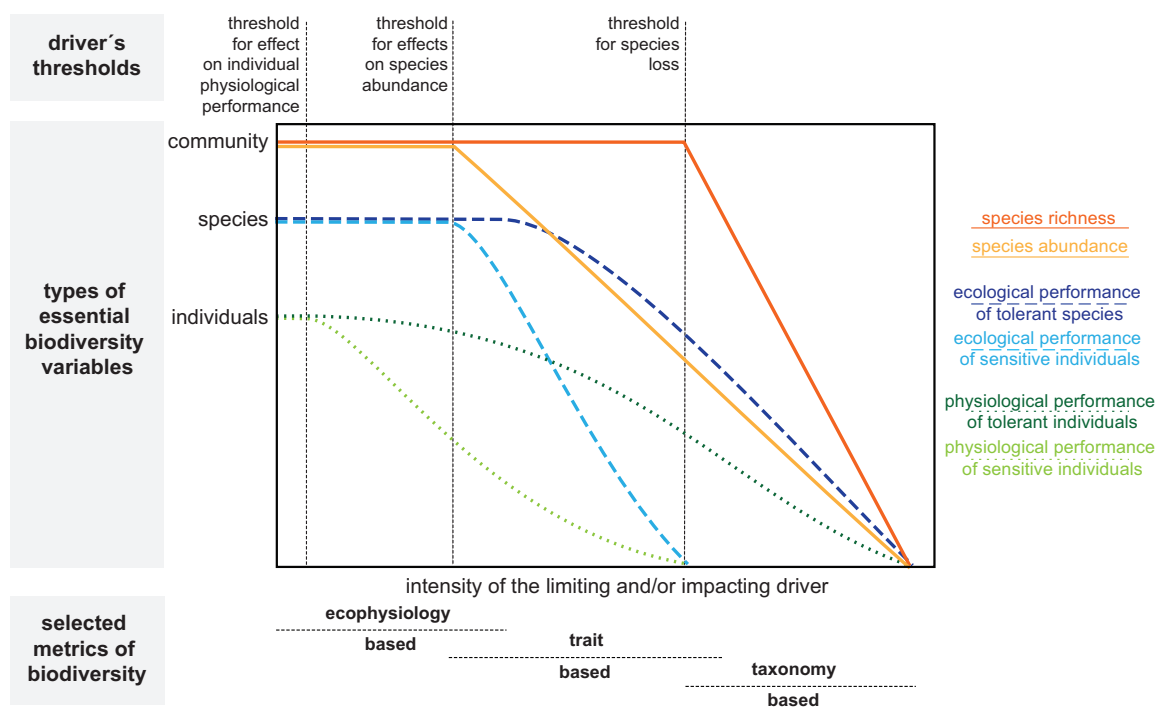

Fig. 7.8 Effect of the driver's intensity on Essential Biodiversity Variables, from individuals' performance to communities. Increasing intensity of the driver will affect sensitive species before tolerant ones, leading to changes in species abundances and consequently to changes in community functional characteristics, reflected by trait-based metrics. A higher intensity of the driver may culminate in species loss, reflected by taxonomic based metrics

mentioned in Sect. 7.3.1, may be due not only to the pressure drivers but also to biotic interactions (de Bello et al. 2012). If the pressure driver persists in time or increases its intensity, changes in ecological performance may culminate in species extinction or their substitution by others with specific traits that make them more tolerant to the pressure driver (Grime and Díaz 2006). Those less tolerant species may be filtered out of the community, affecting species composition and, ultimately, species richness (Fig. 7.8).

\subsubsection{Intraspecific Trait Variation}

It is known that species response to environmental drivers and their effect on ecosystem functioning depend on their characteristics, namely on their functional traits (Hooper et al. 2005; de Bello et al. 2010). For that reason, functional trait-based metrics are emerging as better indicators to quantify changes in ecosystems in response to global change drivers (Díaz and Cabido 1997; Díaz et al. 2007; Lavorel et al. 2011; Mouillot et al. 2013). Functional traits are species attributes, measurable at the individual level, that influence their responses to environmental conditions (by affecting their fitness), or determine their influence on ecosystem properties (Lavorel and Garnier 2002; Hooper et al. 2005). This approach can quantify compositional shifts accounting for species functional redundancy or uniqueness, and has 
the potential to be both universal and applicable at broad spatial scales (to compare very distinct communities), unlike some taxonomic diversity metrics, because it is not linked to species identity per se. Thus, in a case where compositional shifts occur, these metrics enable us to identify which group of species declines (i.e. sensitive species) and which remains (Fig. 7.7).

When studies are focused on the turnover of species (and their traits) in communities and compared across space or over time, the most frequent procedure is to use one mean trait value per species, ignoring trait variation within species. The trait value of each species (mean, range or categories) is then "weighted" by their abundance, to obtain trait-based metrics at the community level. However, some traits are more plastic than others, and may show a high intraspecific variation along environmental gradients (e.g. plant specific leaf area). In general, intraspecific trait variability should be also considered: (i) for more ubiquitous species showing high plasticity along environmental gradients; (ii) in communities with a low turnover in species composition; or (iii) in studies addressing trait variations at finer spatial scales.

Plant trait data may be obtained locally, using standard methodologies (PérezHarguindeguy et al. 2013), or retrieved from scientific literature or trait databases (Kattge et al. 2011). The first approach is considered crucial in the study of processes acting at the plot-scale (e.g. niche partitioning), while the use of database values is considered acceptable for studies at the site-level or at broader scales (Albert et al. 2011; Cordlandwehr et al. 2013; Shipley et al. 2016). Given that measuring species traits is often laborious and time consuming, and not always possible, trait databases are expected to support the change in paradigm from species to traitbased ecology at the global scale. However, trait data available in databases is still insufficient, and lacks large geographical coverage (Kattge et al. 2011). Trait data gaps are more pronounced, for instance, in northern and central Africa, parts of South America, southern and western Asia (Kattge et al. 2011). Thus, trait-based studies should contribute to fulfil trait data gaps as much as possible.

\subsubsection{Functional Trait Metrics}

Trait-based metrics may be described by several metrics comprising either the mean of functional traits, often called functional structure, or their range or dissimilarity, i.e. functional diversity (Díaz et al. 2007; Lavorel et al. 2008). Both were reported to respond to major environmental drivers or biotic interactions, and to affect major ecosystem processes like primary production or decomposition rates (de Bello et al. 2010; Mouillot et al. 2011, 2013; Valencia et al. 2015). The most widely used metric to measure functional structure at the community-level is the community-weighted mean (CWM) (Garnier et al. 2007). This metric reflects the dominant traits in a community, and derives from the "mass ratio hypothesis", according to which the effects of communities on ecosystem processes are largely determined by the traits of the dominant species (Grime 1998). CWM enables the quantification of community shifts in mean trait values due to environmental selection for certain traits, 
associated to changes in the abundance of dominant species (Mouillot et al. 2013). For instance, CWM metrics of epiphytic lichen traits and vascular plants were shown to be related to aridity, having the potential to work as indicators of its effects in drylands (Matos et al. 2015; Nunes et al. 2017).

Functional diversity (FD) shows the degree of functional dissimilarity within the community and can be expressed through various indices (Mason et al. 2005; Villeger et al. 2008; Laliberte and Legendre 2010). FD may be used to quantify the decrease or increase in trait dissimilarity in response to driver's intensity compared to a random expectation (i.e. trait convergence or divergence, respectively). For instance, some drivers may act as abiotic filters on communities, selecting for species with similar "more adapted" trait values, i.e., causing trait convergence. This has been found in vascular plant traits of Mediterranean dryland communities, as a response to increasing aridity (Nunes et al. 2017). Following the "niche complementarity hypothesis", a higher FD is thought to reflect an increase in complementarity in resource use between species, and thus an increase in ecosystem functioning (Tilman et al. 1997). Similarly to taxonomic diversity, FD may be divided into three components namely, functional richness, functional evenness, and functional dispersion (Mason et al. 2005). Functional dispersion, which considers trait abundance in addition to richness, has shown a better predictive ability than, for instance, functional richness (Schleuter et al. 2010; Mouillot et al. 2011). Functional diversity also allows the assessment of ecosystems' resilience towards disturbance drivers. The greater the presence of functionally similar species (higher functional redundancy), the higher the probability that disturbance-induced local extinctions of species will be compensated by the presence of similar species, ensuring higher ecosystem resilience (Pillar et al. 2013).

In short, functional trait-based metrics enable a universal and mechanistic understanding of species response to environmental drivers (Mason and de Bello 2013) and may improve predictions of the effect of global change drivers on biodiversity and on ecosystem functioning if drivers have an intermediate intensity (Suding et al. 2008).

\subsubsection{Multi-trait Metrics}

Over the last decade, several multi-trait metrics have been developed with the aim of resuming the functional diversity of multiple traits into a single FD value, estimating the "functional trait space" occupied by a community (Villeger et al. 2008; Laliberte and Legendre 2010; Schleuter et al. 2010). However, the integration of multiple traits into one metric has to take into account single-trait trends and their possible co-variation, to avoid misinterpretation (Butterfield and Suding 2013). Different traits may show divergent responses to environmental variation due, for instance, to trade-offs among species strategies. Another point to consider is that different traits may be redundant, i.e. convey the same information. Thus, joining them in a single FD value may overestimate their importance in relation to other traits. Two solutions may be adopted to avoid redundancy. The first one is to 
condense the information of single-traits FD into main axes of functional specialization, with techniques that reduce trait data dimensionality in the most informative variation axis, e.g. multivariate methods such as principal components analysis. Alternatively, and considering that correlated traits may not give exactly the same information, one may include all traits in a composite metric, giving a lower weight to correlated traits. However, in either case, it is important to start by checking for each particular context whether the considered traits co-vary or not, as species may show different combinations of traits under different environments, to maximize their performance (Maire et al. 2013; Volis and Bohrer 2013).

\subsubsection{Taxonomic Diversity Metrics}

Assessing biodiversity changes has largely relied on species richness metrics (i.e. a biodiversity-based taxonomy metrics) (Cadotte et al. 2011; Pereira et al. 2013). This was done firstly because this metric directly addresses biodiversity loss, enabling an assessment of the state of biodiversity change in relation to systematic loss. For several years, this metrics revealed highly effective in quantifying biodiversity changes in relation to drivers of great intensity (e.g. sulphur dioxide pollution), revealing trends of declining biodiversity (Cardinale et al. 2012; Hooper et al. 2012). In taxonomic diversity metrics, this is considered the $\alpha$ biodiversity component, which measures the diversity of spatially defined units (Magurran 2013).

Though undeniably useful to measure species loss, this metrics application has revealed some limitations. At the global scale, more than a sharp trend of systematic species loss over time, we seem to be witnessing consistent compositional shifts (Dornelas et al. 2014). These compositional shifts depict the $\beta$ component of biodiversity that measures spatial or temporal differences in composition between communities. The intensity and time of action of the drivers may be responsible for this. The most important drivers in the recent past (Fig. 7.4) have declined its intensity, while the new emerging ones have lower intensities at present, so only in a few years-time, with their continuous action, we will start to observe consistent declines (see Sects. 7.1.2 and 7.1.3). The adoption of measures to control industrial and urban pollutants emissions (e.g. sulphur dioxide or lead) has successfully reduced their levels in the atmosphere (Fenger 2009), since they peaked in late 1970s (Fig. 7.4). Since then, other drivers such as nitrogen pollution or even climate change, became more important (Fig. 7.4). Nonetheless, given their character, intensity, or still short time of action, they seem to trigger compositional shifts more than species loss (Balmford et al. 2003; Dornelas et al. 2014). This happens because species richness may not only be unresponsive, but it may also respond idiosyncratically or peak at intermediate levels of disturbance, potentially showing no signal of change (Mouillot et al. 2013). However, contemplating only metrics of the $\beta$ component of taxonomic diversity may also reveal insufficient from an ecosystem viewpoint. They are unable to account for species functional redundancy or uniqueness in the ecosystems when such compositional shifts occur, disregarding species functional role in the ecosystems (Petchey and Gaston 2006; Cadotte et al. 2011). For 
example, in a recent work, while a decreasing trend was found for functional diversity of several plant traits along a spatial climatic gradient in Mediterranean drylands, no pattern was observed for species richness (Nunes 2017; Nunes et al. 2017). Accordingly, other metrics that maximize tracking changes with a lowest effort should be considered in this context.

Thus, under intermediate driver's intensity a trait-based analysis should perform better, whereas under a strong driver's intensity a taxonomic analysis may be more cost-effective (Fig. 7.8).

\subsubsection{Surrogates of Ecosystem Structure and Functioning Change from Remote Sensing}

Making decisions regarding the conservation of biodiversity and the maintenance of ecosystem services, fostered the need to study indicators and/or surrogates that reflect the structure of ecosystems in a more in-depth way. Ecosystems are complex systems of energy and matter exchange, where a series of ecological processes operate at different scales and with different impacts on their functioning, dependent on their biodiversity. In turn, these processes respond to several drivers that can act simultaneously and interact, often in a non-linear way. This complicates how we can assess the integrity of ecosystems and the state of its processes.

Many of the indicators and/or surrogates used to measure the state of ecosystems do not consider the different effects that drivers have on the ecosystem they act upon, and on their degree of resilience. Measuring the impact on ecosystems is much more complex than measuring the drivers limiting or impacting them. Ecological indicators or surrogates are used to measure the effects of the drivers on the structure and functioning of ecosystems. They are used to communicate environmental data to stakeholders by helping describe them in a simpler and more concise way, more easily understood and used by non-scientists to make management decisions (Lindenmayer et al. 2015). Ecological indicators can be used to diagnose the cause of an environmental problem, to assess the effects of environmental conditions on ecosystem functioning or to provide an early warning signal in the event of changes in the environment. However, ecological indicators are expensive to use at the global scale, being commonly replaced by surrogates based on remote sensing. Before its use, the relationship between the ecological indicators and the surrogates must first be modelled (Fig. 7.3).

Of the six components of the Essential Biodiversity Variables, two can be comprehensively assessed by remote sensing, namely those related to ecosystem structure and ecosystem functioning (Pereira et al. 2013). Common examples include the use of NDVI - normalized difference vegetation index, as a surrogate of vegetation vigour (Gaitan et al. 2013), or the use of other wavelengths to infer measures of vegetation physiological status (Nestola et al. 2018). Remote sensing is also used to directly monitor species and populations, although this remains dependent on the 
size of such species and populations (Vihervaara et al. 2017). Remote sensing measures, offer a major advantage over ground measurements of species and populations in field assessments: they allow upscaling and/or generalizing spatial and temporal cover, which ground measures cannot provide. It also gives us the ability to look to ecosystems with a holistic perspective, for example allowing to look for critical thresholds resulting from multiple non-linear interactions (Scheffer et al. 2009), or to search for emergent properties, i.e., ecosystem properties that do not occur when ecosystems are considered isolated. The importance of remote sensing led to the development of the concept of the Satellite Remote Sensing - Essential Biodiversity Variables by the Group on Earth Observations - Biodiversity Observation Network (Pettorelli et al. 2016). Those are, within the Essential Biodiversity Variables, the ones that need remote sensing to be quantified.

Besides structure and functioning, the effects of many drivers related with biodiversity change can also be measured by remote sensing, including global change drivers like land-use change (Steffen et al. 2015). However, the link that relates ecosystem structure and functioning surrogates to its drivers is still missing. As in Sect. 7.3.2 dealing with species and communities, it is important to use the response to drivers to select the most appropriate remote sensing surrogates of ecosystem structure and functioning. This link would not only allow a better selection of the most appropriate surrogates of ecosystem structure and functioning, but also to upscale the knowledge obtained through a modelling approach.

Modelling approaches can be more direct (e.g. modelling changes in vegetation density by NDVI caused by frequency of wildfires) or more mechanistic (e.g. modelling the response of tree vitality to drought induced by climate change and mediated by insect's outbreaks). In either case, models' contribution would highly support the use of remote sensing in estimating ecosystem structure and functioning as surrogates of Essential Biodiversity Variables. The inclusion of explicit links to drivers in these models provides a much needed generalization capacity, and the possibility to track change over time and space at larger geographical scales. More specifically, that link would support the GEO-BON Global Biodiversity Change Indicators "Species distribution in habitats" and "Biodiversity loss by habitat degradation" (GEO BON 2015).

\subsection{Final Remarks}

There is a strong need for measuring biodiversity change and/or loss at the global scale and over time, to comply with all national and international conventions that protect species, habitats and ecosystems. Despite this, our main objective should be, at least, to live on Earth in a sustainable way, assuring the delivery of provision, cultural and regulation ecosystem services that allow our well-being. Measuring all forms of biodiversity everywhere and over time is an impossible task. That's why the framework of Essential Biodiversity Variables was developed, reducing the forms of biodiversity to six types ("genetic composition," "species populations," 
"species traits," “community composition," "ecosystem structure," and "ecosystem function" (Pereira et al. 2013)). However, even reducing it to six forms of biodiversity, it is not possible to measure all taxa relevant for the maintenance of the delivery of ecosystem services. Thus, we need to find good surrogates that can work as Biodiversity Change Metrics of the Essential Biodiversity Variables.

In this work, we expect biodiversity in the Anthropocene to be changed, in its different facets, by limiting and impacting drivers. We propose that a driver's intensity is determinant to the response of the different biodiversity change metrics. We expect low intensity drivers to influence the response of individual's physiological performance, and propose that Biodiversity Change Metrics should be ecophysiological-based in that case. At intermediate levels of driver's intensity, we expect the most cost-effective Biodiversity Change Metrics to be trait-based. Finally, in situations of strong driver's intensity we expect decreases in abundance and species loss, proposing a taxonomic-based approach as the most cost-effective to detect biodiversity changes. We further discuss the use of remote sensing data to measure changes in some of these indicators or surrogates of Essential Biodiversity Variables, particularly those reflecting ecosystem structure and functioning, allowing to upscale and/or generalize spatial and temporal information.

Acknowledgements We would like to acknowledge the financial support of the following projects: (i) NitroPortugal [European Union's Horizon 2020 research and innovation programme under grant agreement No 692331]; (ii) INMS, Towards the Establishment of an International Nitrogen Management System (INMS); (iii) ChangeTracker, financed by FCT, PTDC/ AAG-GLO/0045/2014.

\section{References}

Albert, C. H., Grassein, F., Schurr, F. M., Vieilledent, G., \& Violle, C. (2011). When and how should intraspecific variability be considered in trait-based plant ecology? Perspectives in Plant Ecology, Evolution and Systematics, 13, 217-225. https://doi.org/10.1016/j. ppees.2011.04.003.

Balmford, A., Green, R. E., \& Jenkins, M. (2003). Measuring the changing state of nature. Trends in Ecology \& Evolution, 18, 326-330. https://doi.org/10.1016/S0169-5347(03)00067-3.

de Bello, F., Lavorel, S., Diaz, S., Harrington, R., Cornelissen, J. H. C., Bardgett, R. D., Berg, M. P., Cipriotti, P., Feld, C. K., Hering, D., da Silva, P. M., Potts, S. G., Sandin, L., Sousa, J. P., Storkey, J., Wardle, D. A., \& Harrison, P. A. (2010). Towards an assessment of multiple ecosystem processes and services via functional traits. Biodiversity and Conservation, 19, 2873-2893. https://doi.org/10.1007/s10531-010-9850-9.

de Bello, F., Price, J. N., Muenkemueller, T., Liira, J., Zobel, M., Thuiller, W., Gerhold, P., Goetzenberger, L., Lavergne, S., Leps, J., Zobel, K., \& Paertel, M. (2012). Functional species pool framework to test for biotic effects on community assembly. Ecology, 93, 2263-2273. https://doi.org/10.1890/11-1394.1.

de Bello, F., Lavorel, S., Lavergne, S., Albert, C. H., Boulangeat, I., Mazel, F., \& Thuiller, W. (2013). Hierarchical effects of environmental filters on the functional structure of plant communities: A case study in the French Alps. Ecography, 36, 393-402. https://doi. org/10.1111/j.1600-0587.2012.07438.x. 
Bockstaller, C., \& Girardin, P. (2003). How to validate environmental indicators. Agricultural Systems, 76, 639-653. https://doi.org/10.1016/S0308-521X(02)00053-7.

Brooks, T. M., Lamoreux, J. F., \& Soberón, J. (2014). Ipbes ₹ ipcc. Trends in Ecology \& Evolution, 29, 543-545. https://doi.org/10.1016/j.tree.2014.08.004.

Brummitt, N., Regan, E. C., Weatherdon, L. V., Martin, C. S., Geijzendorffer, I. R., Rocchini, D., Gavish, Y., Haase, P., Marsh, C. J., \& Schmeller, D. S. (2017). Taking stock of nature: Essential biodiversity variables explained. Biological Conservation, 213, 252-255. https://doi. org/10.1016/j.biocon.2016.09.006.

Butchart, S. H., Walpole, M., Collen, B., Van Strien, A., Scharlemann, J. P., Almond, R. E., Baillie, J. E., Bomhard, B., Brown, C., \& Bruno, J. (2010). Global biodiversity: Indicators of recent declines. Science, 328, 1164-1168. https://doi.org/10.1126/science.1187512.

Butterfield, B. J., \& Suding, K. N. (2013). Single-trait functional indices outperform multi-trait indices in linking environmental gradients and ecosystem services in a complex landscape. Journal of Ecology, 101, 9-17. https://doi.org/10.1111/1365-2745.12013.

Cadotte, M. W., Carscadden, K., \& Mirotchnick, N. (2011). Beyond species: Functional diversity and the maintenance of ecological processes and services. Journal of Applied Ecology, 48, 1079-1087. https://doi.org/10.1111/j.1365-2664.2011.02048.x.

Canadell, J. G., Le Quéré, C., Raupach, M. R., Field, C. B., Buitenhuis, E. T., Ciais, P., Conway, T. J., Gillett, N. P., Houghton, R., \& Marland, G. (2007). Contributions to accelerating atmospheric $\mathrm{CO} 2$ growth from economic activity, carbon intensity, and efficiency of natural sinks. Proceedings of the National Academy of Sciences, 104, 18866-18870. https://doi.org/10.1073/ pnas.0702737104.

Cardinale, B. J., Duffy, J. E., Gonzalez, A., Hooper, D. U., Perrings, C., Venail, P., Narwani, A., Mace, G. M., Tilman, D., Wardle, D. A., Kinzig, A. P., Daily, G. C., Loreau, M., Grace, J. B., Larigauderie, A., Srivastava, D. S., \& Naeem, S. (2012). Biodiversity loss and its impact on humanity. Nature, 486, 59-67. https://doi.org/10.1038/nature11148.

CBD. (2014). Convention on biological diversity. Global Biodiversity Outlook 4. Montréal, 155 pages. https://www.cbd.int/gbo4/. Accessed 5 Nov 2017.

Chandler, M., See, L., Copas, K., Bonde, A. M., López, B. C., Danielsen, F., Legind, J. K., Masinde, S., Miller-Rushing, A. J., \& Newman, G. (2017). Contribution of citizen science towards international biodiversity monitoring. Biological Conservation, 213, 280-294. https:// doi.org/10.1016/j.biocon.2016.09.004.

Collen, B., \& Nicholson, E. (2014). Taking the measure of change. Science, 346, 166-167. https:// doi.org/10.1126/science.1255772.

Collen, B., Ram, M., Zamin, T., \& McRae, L. (2008). The tropical biodiversity data gap: Addressing disparity in global monitoring. Tropical Conservation Science, 1, 75-88. https:// doi.org/10.1177/194008290800100202.

Collen, B., Loh, J., Whitmee, S., McRAE, L., Amin, R., \& Baillie, J. E. (2009). Monitoring change in vertebrate abundance: The living planet index. Conservation Biology, 23, 317-327. https:// doi.org/10.1111/j.1523-1739.2008.01117.x.

Colwell, R. K., \& Fuentes, E. R. (1975). Experimental studies of the niche. Annual Review of Ecology and Systematics, 6, 281-310. https://doi.org/10.1146/annurev.es.06.110175.001433.

Colwell, R. K., \& Rangel, T. F. (2009). Hutchinson's duality: The once and future niche. Proceedings of the National Academy of Sciences, 106, 19651-19658. https://doi.org/10.1073/ pnas.0901650106.

Cordlandwehr, V., Meredith, R. L., Ozinga, W. A., Bekker, R. M., Groenendael, J. M., \& Bakker, J. P. (2013). Do plant traits retrieved from a database accurately predict on-site measurements? Journal of Ecology, 101, 662-670. https://doi.org/10.1111/1365-2745.12091.

Cornwell, W. K., \& Ackerly, D. D. (2009). Community assembly and shifts in plant trait distributions across an environmental gradient in coastal California. Ecological Monographs, 79, 109-126. https://doi.org/10.1890/07-1134.1.

Díaz, S., \& Cabido, M. (1997). Plant functional types and ecosystem function in relation to global change. Journal of Vegetation Science, 8, 463-474. https://www.jstor.org/stable/3237198. 
Díaz, S., Lavorel, S., Chapin, F. S., III, Tecco, P. A., Gurvich, D. E., \& Grigulis, K. (2007). Functional diversity - At the crossroads between ecosystem functioning and environmental filters. In J. G. Canadell, D. E. Pataki, \& L. F. Pitelka (Eds.), Terrestrial ecosystems in a changing world (Global change - The IGBP series) (pp. 81-91). Berlin/Heidelberg: Springer.

Dornelas, M., Gotelli, N. J., McGill, B., Shimadzu, H., Moyes, F., Sievers, C., \& Magurran, A. E. (2014). Assemblage time series reveal biodiversity change but not systematic loss. Science, 344, 296-299. https://doi.org/10.1126/science.1248484.

EEA. (2014). European environment agency. Air quality in Europe - 2014 report (EEA technical report No. 5/2014). https://doi.org/10.2800/22775.

EEA. (2016). European environment agency. Air quality in Europe - 2016 report (EEA technical report). https://doi.org/10.2800/80982.

Fenger, J. (2009). Air pollution in the last 50 years-From local to global. Atmospheric Environment, 43, 13-22. https://doi.org/10.1016/j.atmosenv.2008.09.061.

Fusco, G., \& Minelli, A. (2010). Phenotypic plasticity in development and evolution: facts and concepts. Philosophical Transactions of the Royal Society B, 365, 547-556. https://doi. org/10.1098/rstb.2009.0267.

Gaitan, J. J., Bran, D., Oliva, G., Ciari, G., Nakamatsu, V., Salomone, J., Ferrante, D., Buono, G., Massara, V., Humano, G., Celdran, D., Opazo, W., \& Maestre, F. T. (2013). Evaluating the performance of multiple remote sensing indices to predict the spatial variability of ecosystem structure and functioning in Patagonian steppes. Ecological Indicators, 34, 181-191. https:// doi.org/10.1016/j.ecolind.2013.05.007.

Garnier, E., Lavorel, S., Ansquer, P., Castro, H., Cruz, P., Dolezal, J., Eriksson, O., Fortunel, C., Freitas, H., \& Golodets, C. (2007). Assessing the effects of land-use change on plant traits, communities and ecosystem functioning in grasslands: a standardized methodology and lessons from an application to 11 European sites. Annals of Botany, 99, 967-985. https://doi. org/10.1093/aob/mcl215.

Geijzendorffer, I. R., Regan, E. C., Pereira, H. M., Brotons, L., Brummitt, N., Gavish, Y., Haase, P., Martin, C. S., Mihoub, J. B., \& Secades, C. (2016). Bridging the gap between biodiversity data and policy reporting needs: An Essential Biodiversity Variables perspective. Journal of Applied Ecology, 53, 1341-1350. https://doi.org/10.1111/1365-2664.12417.

GEO BON. (2015). The group on earth observations biodiversity observation network. Global biodiversity change indicators: Model-based integration of remote-sensing \& in situ observations that enables dynamic updates and transparency at low cost. http://orbit.dtu.dk/ files/118107442/GBCI_Version1.2_low_Biodiversity_Index.pdf. Version 1.2, Nov 2015.

Grantham, H. S., Pressey, R. L., Wells, J. A., \& Beattie, A. J. (2010). Effectiveness of biodiversity surrogates for conservation planning: Different measures of effectiveness generate a kaleidoscope of variation. PLoS One, 5, e11430. https://doi.org/10.1371/journal.pone.0011430.

Grime, J. P. (1998). Benefits of plant diversity to ecosystems: Immediate, filter and founder effects. Journal of Ecology, 86, 902-910. https://doi.org/10.1046/j.1365-2745.1998.00306.x.

Grime, J. P., \& Díaz, S. (2006). Trait convergence and trait divergence in herbaceous plant communities: Mechanisms and consequences. Journal of Vegetation Science, 17, 255-260. https:// doi.org/10.1111/j.1654-1103.2006.tb02444.x.

Halpern, B. S., Longo, C., Hardy, D., McLeod, K. L., Samhouri, J. F., Katona, S. K., Kleisner, K., Lester, S. E., O'Leary, J., \& Ranelletti, M. (2012). An index to assess the health and benefits of the global ocean. Nature, 488, 615-620. https://doi.org/10.1038/nature11397.

Henle, K., Potts, S., Kunin, W., Matsinos, Y., Simila, J., Pantis, J., Grobelnik, V., Penev, L., \& Settele, J. (2014). Scaling in ecology and biodiversity conservation. Advanced Books, 1, e1169. https://doi.org/10.3897/ab.e1169.

Holling, C. S. (1973). Resilience and stability of ecological systems. Annual Review of Ecology and Systematics, 4, 1-23. https://doi.org/10.1146/annurev.es.04.110173.000245.

Hooper, D. U., Chapin, F., Ewel, J., Hector, A., Inchausti, P., Lavorel, S., Lawton, J., Lodge, D., Loreau, M., \& Naeem, S. (2005). Effects of biodiversity on ecosystem functioning: A consensus of current knowledge. Ecological Monographs, 75, 3-35. https://doi.org/10.1890/04-0922. 
Hooper, D. U., Adair, E. C., Cardinale, B. J., Byrnes, J. E., Hungate, B. A., Matulich, K. L., Gonzalez, A., Duffy, J. E., Gamfeldt, L., \& O’Connor, M. I. (2012). A global synthesis reveals biodiversity loss as a major driver of ecosystem change. Nature, 486, 105-108. https://doi. org/10.1038/nature11118.

Hortal, J., de Bello, F., Diniz-Filho, J. A. F., Lewinsohn, T. M., Lobo, J. M., \& Ladle, R. J. (2015). Seven shortfalls that beset large-scale knowledge of biodiversity. Annual Review of Ecology, Evolution, and Systematics, 46, 523-549. https://doi.org/10.1146/ annurev-ecolsys-112414-054400.

Hunter, M., Westgate, M., Barton, P., Calhoun, A., Pierson, J., Tulloch, A., Beger, M., Branquinho, C., Caro, T., \& Gross, J. (2016). Two roles for ecological surrogacy: Indicator surrogates and management surrogates. Ecological Indicators, 63, 121-125. https://doi.org/10.1016/j. ecolind.2015.11.049.

Hutchinson, G. E. (1957). Cold spring harbor symposium on quantitative biology. Concluding Remarks, 22, 415-427. https://doi.org/10.1101/SQB.1957.022.01.039.

Hutchinson, G. E. (1991). Population studies: Animal ecology and demography. Bulletin of Mathematical Biology, 53, 193-213. https://doi.org/10.1007/BF02464429.

IPCC. (2007). Climate change 2007: Synthesis report. Contribution of working groups I, II and III to the fourth assessment report of the intergovernmental panel on climate change. Geneva: IPCC.

Kattge, J., Diaz, S., Lavorel, S., Prentice, I. C., Leadley, P., Bönisch, G., Garnier, E., Westoby, M., Reich, P. B., \& Wright, I. J. (2011). TRY-A global database of plant traits. Global Change Biology, 17, 2905-2935. https://doi.org/10.1111/j.1365-2486.2011.02451.x.

Kot, C. Y., Fujioka, E., Hazen, L. J., Best, B. D., Read, A. J., \& Halpin, P. N. (2010). Spatiotemporal gap analysis of OBIS-SEAMAP project data: Assessment and way forward. PLoS One, 5, e12990. https://doi.org/10.1371/journal.pone.0012990.

Laliberte, E., \& Legendre, P. (2010). A distance-based framework for measuring functional diversity from multiple traits. Ecology, 91, 299-305. https://doi.org/10.1890/08-2244.1.

Lavorel, S., \& Garnier, E. (2002). Predicting changes in community composition and ecosystem functioning from plant traits: Revisiting the Holy Grail. Functional Ecology, 16, 545-556. https://doi.org/10.1046/j.1365-2435.2002.00664.x.

Lavorel, S., Grigulis, K., McIntyre, S., Williams, N. S. G., Garden, D., Dorrough, J., Berman, S., Quetier, F., Thebault, A., \& Bonis, A. (2008). Assessing functional diversity in the field - Methodology matters! Functional Ecology, 22, 134-147. https://doi. org/10.1111/j.1365-2435.2007.01339.x.

Lavorel, S., de Bello, F., Grigulis, K., Lepš, J., Garnier, E., Castro, H., Dolezal, J., Godolets, C., Quétier, F., \& Thébault, A. (2011). Response of herbaceous vegetation functional diversity to land use change across five sites in Europe and Israel. Israel Journal of Ecology \& Evolution, 57, 53-72. https://doi.org/10.1560/IJEE.57.1-2.53.

Lindenmayer, D., Pierson, J., Barton, P., Beger, M., Branquinho, C., Calhoun, A., Caro, T., Greig, H., Gross, J., \& Heino, J. (2015). A new framework for selecting environmental surrogates. Science of the Total Environment, 538, 1029-1038. https://doi.org/10.1016/j. scitotenv.2015.08.056.

Magurran, A. E. (2013). Measuring biological diversity. Oxford: John Wiley \& Sons.

Maire, V., Gross, N., Hill, D., Martin, R., Wirth, C., Wright, I. J., \& Soussana, J.-F. (2013). Disentangling coordination among functional traits using an individual-centred model: Impact on plant performance at intra-and inter-specific levels. PLoS One, 8, e77372. https://doi. org/10.1371/journal.pone.0077372.

Mason, N. W. H., \& de Bello, F. (2013). Functional diversity: A tool for answering challenging ecological questions. Journal of Vegetation Science, 24, 777-780. https://doi.org/10.1111/ jvs.12097.

Mason, N. W. H., Mouillot, D., Lee, W. G., \& Wilson, J. B. (2005). Functional richness, functional evenness and functional divergence: The primary components of functional diversity. Oikos, 111, 112-118. https://doi.org/10.1111/j.0030-1299.2005.13886.x. 
Matos, P., Pinho, P., Aragón, G., Martínez, I., Nunes, A., Soares, A. M., \& Branquinho, C. (2015). Lichen traits responding to aridity. Journal of Ecology, 103, 451-458. https://doi. org/10.1111/1365-2745.12364.

Matos, P., Geiser, L., Hardman, A., Glavich, D., Pinho, P., Nunes, A., Soares, A. M., \& Branquinho, C. (2017). Tracking global change using lichen diversity: Towards a globalscale ecological indicator. Methods in Ecology and Evolution, 8, 788-798. https://doi. org/10.1111/2041-210X.12712.

McGeoch, M. A. (1998). The selection, testing and application of terrestrial insects as bioindicators. Biological Reviews, 73, 181-201. https://doi.org/10.1111/j.1469-185X.1997.tb00029.x.

McGill, B. J. (2012). Trees are rarely most abundant where they grow best. Journal of Plant Ecology, 5, 46-51. https://doi.org/10.1093/jpe/rtr036.

MEA. (2005). Milliennium ecosystem assessment. Ecosystems and human well-being: Synthesis. Washington, DC: Island Press.

Meadows, D. H., Meadows, D. L., Randers, J., \& Behrens, W. W. (1972). The limits to growth. New York: Universe Books.

Mellin, C., Delean, S., Caley, J., Edgar, G., Meekan, M., Pitcher, R., Przeslawski, R., Williams, A., \& Bradshaw, C. (2011). Effectiveness of biological surrogates for predicting patterns of marine biodiversity: A global meta-analysis. PLoS One, 6, e20141. https://doi.org/10.1371/ journal.pone.0020141.

Mora, C., Tittensor, D. P., \& Myers, R. A. (2008). The completeness of taxonomic inventories for describing the global diversity and distribution of marine fishes. Proceedings of the Royal Society of London B: Biological Sciences, 275, 149-155. https://doi.org/10.1098/ rspb.2007.1315.

Mouillot, D., Villeger, S., Scherer-Lorenzen, M., \& Mason, N. W. H. (2011). Functional structure of biological communities predicts ecosystem multifunctionality. PLoS One, 6, e17476. https:// doi.org/10.1371/journal.pone.0017476.

Mouillot, D., Graham, N. A. J., Villeger, S., Mason, N. W. H., \& Bellwood, D. R. (2013). A functional approach reveals community responses to disturbances. Trends in Ecology \& Evolution, 28, 167-177. https://doi.org/10.1016/j.tree.2012.10.004.

Nestola, E., Scartazza, A., Di Baccio, D., Castagna, A., Ranieri, A., Cammarano, M., Mazzenga, F., Matteucci, G., \& Calfapietra, C. (2018). Are optical indices good proxies of seasonal changes in carbon fluxes and stress-related physiological status in a beech forest? Science of the Total Environment, 612, 1030-1041. https://doi.org/10.1016/j.scitotenv.2017.08.167.

Niemeijer, D., \& de Groot, R. S. (2008). A conceptual framework for selecting environmental indicator sets. Ecological Indicators, 8, 14-25. https://doi.org/10.1016/j.ecolind.2006.11.012.

Noss, R. F. (1990). Indicators for monitoring biodiversity: A hierarchical approach. Conservation Biology, 4, 355-364. https://doi.org/10.1111/j.1523-1739.1990.tb00309.x.

Nunes, A. (2017). Plant functional response to desertification and land degradation - Contribution to restoration strategies. Aveiro: Universidade de Aveiro. http://hdl.handle.net/10773/18814.

Nunes, A., Köbel, M., Pinho, P., Matos, P., de Bello, F., Correia, O., \& Branquinho, C. (2017). Which plant traits respond to aridity? A critical step to assess functional diversity in Mediterranean drylands. Agricultural and Forest Meteorology, 239, 176-184. https://doi. org/10.1016/j.agrformet.2017.03.007.

Pereira, H. M., \& Cooper, H. D. (2006). Towards the global monitoring of biodiversity change. Trends in Ecology \& Evolution, 21, 123-129. https://doi.org/10.1016/j.tree.2005.10.015.

Pereira, H. M., Navarro, L. M., \& Martins, I. S. (2012). Global biodiversity change: The bad, the good, and the unknown. Annual Review of Environment and Resources, 37, 25-50. https://doi. org/10.1146/annurev-environ-042911-093511.

Pereira, H. M., Ferrier, S., Walters, M., Geller, G. N., Jongman, R. H. G., Scholes, R. J., Bruford, M. W., Brummitt, N., Butchart, S. H. M., Cardoso, A. C., Coops, N. C., Dulloo, E., Faith, D. P., Freyhof, J., Gregory, R. D., Heip, C., Hoeft, R., Hurtt, G., Jetz, W., Karp, D. S., McGeoch, M. A., Obura, D., Onoda, Y., Pettorelli, N., Reyers, B., Sayre, R., Scharlemann, J. P. W., Stuart, S. N., Turak, E., Walpole, M., \& Wegmann, M. (2013). Essential biodiversity variables. Science, 339, 277-278. https://doi.org/10.1126/science.1229931. 
Pérez-Harguindeguy, N., Díaz, S., Garnier, E., Lavorel, S., Poorter, H., Jaureguiberry, P., BretHarte, M., Cornwell, W., Craine, J., \& Gurvich, D. (2013). New handbook for standardised measurement of plant functional traits worldwide. Australian Journal of Botany, 61, 167-234. https://doi.org/10.1071/BT12225.

Petchey, O. L., \& Gaston, K. J. (2006). Functional diversity: Back to basics and looking forward. Ecology Letters, 9, 741-758. https://doi.org/10.1111/j.1461-0248.2006.00924.x.

Pettorelli, N., Wegmann, M., Skidmore, A., Mücher, S., Dawson, T. P., Fernandez, M., Lucas, R., Schaepman, M. E., Wang, T., \& O'Connor, B. (2016). Framing the concept of satellite remote sensing essential biodiversity variables: Challenges and future directions. Remote Sensing in Ecology and Conservation, 2, 122-131. https://doi.org/10.1002/rse2.15.

Pillar, V. D., Blanco, C. C., Mueller, S. C., Sosinski, E. E., Joner, F., \& Duarte, L. D. S. (2013). Functional redundancy and stability in plant communities. Journal of Vegetation Science, 24, 963-974. https://doi.org/10.1111/jvs.12047.

Pollock, L. J., Thuiller, W., \& Jetz, W. (2017). Large conservation gains possible for global biodiversity facets. Nature, 546, 141-144. https://doi.org/10.1038/nature22368.

Proença, V., Martin, L. J., Pereira, H. M., Fernandez, M., McRae, L., Belnap, J., Böhm, M., Brummitt, N., García-Moreno, J., \& Gregory, R. D. (2017). Global biodiversity monitoring: From data sources to essential biodiversity variables. Biological Conservation, 213, 256-263. https://doi.org/10.1016/j.biocon.2016.07.014.

Ribeiro, M. C., Pinho, P., Llop, E., Branquinho, C., Sousa, A. J., \& Pereira, M. J. (2013). Multivariate geostatistical methods for analysis of relationships between ecological indicators and environmental factors at multiple spatial scales. Ecological Indicators, 29, 339-347. https://doi.org/10.1016/j.ecolind.2013.01.011.

Rockström, J., Steffen, W., Noone, K., Persson, Å., Chapin, F. S., Lambin, E. F., Lenton, T. M., Scheffer, M., Folke, C., \& Schellnhuber, H. J. (2009). A safe operating space for humanity. Nature, 461, 472-475. https://doi.org/10.1038/461472a.

Scheffer, M., Carpenter, S., Foley, J. A., Folke, C., \& Walker, B. (2001). Catastrophic shifts in ecosystems. Nature, 413, 591-596. https://doi.org/10.1038/35098000.

Scheffer, M., Bascompte, J., Brock, W. A., Brovkin, V., Carpenter, S. R., Dakos, V., Held, H., van Nes, E. H., Rietkerk, M., \& Sugihara, G. (2009). Early-warning signals for critical transitions. Nature, 461, 53-59. https://doi.org/10.1038/nature08227.

Schleuter, D., Daufresne, M., Massol, F., \& Argillier, C. (2010). A user's guide to functional diversity indices. Ecological Monographs, 80, 469-484. https://doi.org/10.1890/08-2225.1.

Scholes, R. J., Walters, M., Turak, E., Saarenmaa, H., Heip, C. H., Tuama, É. Ó., Faith, D. P., Mooney, H. A., Ferrier, S., \& Jongman, R. H. (2012). Building a global observing system for biodiversity. Current Opinion in Environmental Sustainability, 4, 139-146. https://doi.org/10.1016/j.cosust.2011.12.005.

Serrano, H. C., Antunes, C., Pinto, M. J., Máguas, C., Martins-Loução, M. A., \& Branquinho, C. (2015). The ecological performance of metallophyte plants thriving in geochemical islands is explained by the Inclusive Niche Hypothesis. Journal of Plant Ecology, 8, 41-50. https://doi. org/10.1093/jpe/rtu007.

Shipley, B., De Bello, F., Cornelissen, J. H. C., Laliberté, E., Laughlin, D. C., \& Reich, P. B. (2016). Reinforcing loose foundation stones in trait-based plant ecology. Oecologia, 180, $923-$ 931. https://doi.org/10.1007/s00442-016-3549-x.

Steffen, W., Richardson, K., Rockström, J., Cornell, S. E., Fetzer, I., Bennett, E. M., Biggs, R., Carpenter, S. R., de Vries, W., \& de Wit, C. A. (2015). Planetary boundaries: Guiding human development on a changing planet. Science, 347, 1259855. https://doi.org/10.1126/ science. 1259855 .

Suding, K. N., Lavorel, S., Chapin, F., Cornelissen, J. H., Diaz, S., Garnier, E., Goldberg, D., Hooper, D. U., Jackson, S. T., \& Navas, M. L. (2008). Scaling environmental change through the community-level: A trait-based response-and-effect framework for plants. Global Change Biology, 14, 1125-1140. https://doi.org/10.1111/j.1365-2486.2008.01557.x.

Tilman, D., Knops, J., Wedin, D., Reich, P., Ritchie, M., \& Siemann, E. (1997). The influence of functional diversity and composition on ecosystem processes. Science, 277, 1300-1302. https://doi.org/10.1126/science.277.5330.1300. 
Tittensor, D. P., Walpole, M., Hill, S. L., Boyce, D. G., Britten, G. L., Burgess, N. D., Butchart, S. H., Leadley, P. W., Regan, E. C., \& Alkemade, R. (2014). A mid-term analysis of progress toward international biodiversity targets. Science, 346, 241-244. https://doi.org/10.1126/ science. 1257484.

Turak, E., Brazill-Boast, J., Cooney, T., Drielsma, M., DelaCruz, J., Dunkerley, G., Fernandez, M., Ferrier, S., Gill, M., \& Jones, H. (2017). Using the essential biodiversity variables framework to measure biodiversity change at national scale. Biological Conservation, 213, 264-271. https://doi.org/10.1016/j.biocon.2016.08.019.

UNCBD. (2011). United Nations convention on biological diversity. Strategic plan for biodiversity 2011-2020 and the aichi biodiversity targets. http://www.cbd.int/sp/. Accessed 5 Nov 2017.

Valencia, E., Maestre, F. T., Le Bagousse-Pinguet, Y., Luis Quero, J., Tamme, R., Boerger, L., Garcia-Gomez, M., \& Gross, N. (2015). Functional diversity enhances the resistance of ecosystem multifunctionality to aridity in Mediterranean drylands. New Phytologist, 206, 660-671. https://doi.org/10.1111/nph.13268.

Vihervaara, P., Auvinen, A. P., Mononen, L., Torma, M., Ahlroth, P., Anttila, S., Bottcher, K., Forsius, M., Heino, J., Heliola, J., Koskelainen, M., Kuussaari, M., Meissner, K., Ojala, O., Tuominen, S., Viitasalo, M., \& Virkkala, R. (2017). How essential biodiversity variables and remote sensing can help national biodiversity monitoring. Global Ecology and Conservation, 10, 43-59. https://doi.org/10.1016/j.gecco.2017.01.007.

Villeger, S., Mason, N. W. H., \& Mouillot, D. (2008). New multidimensional functional diversity indices for a multifaceted framework in functional ecology. Ecology, 89, 2290-2301. https:// doi.org/10.1890/07-1206.1.

Volis, S., \& Bohrer, G. (2013). Joint evolution of seed traits along an aridity gradient: Seed size and dormancy are not two substitutable evolutionary traits in temporally heterogeneous environment. New Phytologist, 197, 655-667. https://doi.org/10.1111/nph.12024.

Westgate, M. J., Barton, P. S., Lane, P. W., \& Lindenmayer, D. B. (2014). Global meta-analysis reveals low consistency of biodiversity congruence relationships. Nature Communications, 5 , 3899. https://doi.org/10.1038/ncomms4899.

WMO. (2010). GCOS - Global climate observing system. Implementation plan for the global observing system for climate in support of the UNFCCC (2010 Update). Geneva: WMO Publications.

Zalasiewicz, J., Williams, M., Steffen, W., \& Crutzen, P. (2010). The new world of the Anthropocene 1. Environmental Science \& Technology, 44, 2228-2231. https://doi.org/10.1021/es903118j.

Open Access This chapter is licensed under the terms of the Creative Commons Attribution 4.0 International License (http://creativecommons.org/licenses/by/4.0/), which permits use, sharing, adaptation, distribution and reproduction in any medium or format, as long as you give appropriate credit to the original author(s) and the source, provide a link to the Creative Commons licence and indicate if changes were made.

The images or other third party material in this chapter are included in the chapter's Creative Commons licence, unless indicated otherwise in a credit line to the material. If material is not included in the chapter's Creative Commons licence and your intended use is not permitted by statutory regulation or exceeds the permitted use, you will need to obtain permission directly from the copyright holder.

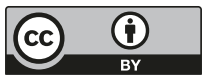

